\title{
Prevalence of self reported stroke in a population in northern England
}

Joanna M L Geddes, Jon Fear, Alan Tennant, Ann Pickering, Micky Hillman, M Anne Chamberlain

\begin{abstract}
Study objective - The aim of this study was to determine the prevalence of stroke survivors in a health district population aged 55 years and over.

Design - This was a point prevalence study using two-stage postal questionnaires sent to an age stratified random sample of the population.

Setting - A district health authority in northern England with a resident population of 723000 .

Subjects - Altogether 18827 residents aged 55 years or over.

Main results - Prevalence was found to increase with age and, apart from the very elderly, males had a higher prevalence than females. Overall prevalence was found to be $46 \cdot 8 / 1000(95 \%$ CI $42 \cdot 5,51 \cdot 6)$. $23 \%$ of respondents reported full recovery from stroke. Cognitive impairments (33\%), problems with lower limbs (33\% for right leg; $27 \%$ for left leg) and speech difficulties $(27 \%)$ were the most common residual impairments.

Conclusions - Current guidelines to purchasers on the provision of services to those who have had a stroke may underestimate prevalence rates by as much as $50 \%$. This could lead to a shortfall in provision of services designed to support people in the months and years following their stroke.
\end{abstract}

(f Epidemiol Community Health 1996;50:140-143)

Rheumatology and Rehabilitation Research Unit, Research School of Medicine,

University of Leeds

J M L Geddes

A Tennant

$M$ Hillman

M A Chamberlain

Leeds Health

Authority,

St Mary's House,

Leeds

J Fear

North Yorkshire

Health Authority,

Sovereign House, York

A Pickering

Correspondence to: Ms J Geddes, Rheumatology and Rehabilitation Research Unit, 36 Clarendon Road, Leeds LS2 9NZ.

Accepted for publication November 1995
The recent reforms within the National Health Service placed an obligation on health purchasing authorities to assess the health needs of their residents. Such assessments will involve a knowledge of prevalence; the proportion of the population affected by a given disease at a given time. Estimating the prevalence of stroke in a population from figures in the published reports is difficult and prone to error. A recent review shows that prevalence, age standardised to the world population, varies from 255/
100000 to $744 / 100000 .^{1}$ The studies from which these figures were obtained came from geographically diverse areas, such as Kashmir, Taiwan, and Denmark, and used different methods of obtaining prevalence rates. Within the United Kingdom a prevalence of 600/ 100000 has been given as a guide to purchasing authorities. $^{2}$

We describe the results from a survey designed to enable a purchasing authority to determine the numbers of people aged 55 years or more, in the population for which they have responsibility, who report that they have experienced a stroke.

\section{Methods}

SAMPLING FRAME AND SIZE

A postal questionnaire was sent to an agestratified random sample of residents of the North Yorkshire Health Authority aged 55 years and over.

The population register of the North Yorkshire Family Health Services Authority, which is coterminous with North Yorkshire District Health Authority, was used as a sampling frame. North Yorkshire is England's largest county, covering about 3200 square miles. It has a resident population of 723000 . The over 55 population was estimated at 210000 in the 1991 census and the proportion of the population aged 65 years and over was $18 \%$, slightly higher than the $16 \%$ estimate for the national population. Almost two thirds (65\%) of residents live in small towns or rural communities, while the remainder live in the six population centres of Harrogate, Northallerton, Scarborough, Skipton, Selby, and York. Sample size was based upon expected incidence, ${ }^{3}$ so as to be able to examine the health care experiences of those who had had a recent stroke. Overall, approximately one in 10 of the over 55 year old population was selected for the screening questionnaire. They were selected from a disproportionately agestratified sample of one in seven of those aged 55 to 64 ; one in 11 of those aged 65 to 74 and one in 21 of those aged 75 years and over.

Table 1 Age and sex specific prevalence rates per 1000 (95\% confidence intervals)

\begin{tabular}{lcccr}
\hline Age group & Male & Female & Total & Unweighted base \\
\hline $55-64$ y & $21 \cdot 6(15 \cdot 0,30 \cdot 2)$ & $11 \cdot 4(6 \cdot 9,17 \cdot 8)$ & $16 \cdot 4(12 \cdot 3,21 \cdot 5)$ & 120 \\
$65-74$ y & $46 \cdot 8(36 \cdot 0,59 \cdot 7)$ & $33 \cdot 9(25 \cdot 6,44 \cdot 0)$ & $39 \cdot 8(33 \cdot 3,47 \cdot 7)$ & 167 \\
$75-84$ y & $110 \cdot 1(87 \cdot 5,136 \cdot 5)$ & $79 \cdot 7(64 \cdot 8,97 \cdot 3)$ & $91 \cdot 1(78 \cdot 5,105 \cdot 7)$ & 94 \\
$85+\mathrm{y}$ & $82 \cdot 2(43 \cdot 7,140 \cdot 5)$ & $104 \cdot 1(77 \cdot 0,137 \cdot 3)$ & $98 \cdot 4(75 \cdot 5,126 \cdot 0)$ & 34 \\
$55+\mathrm{y}$ & $50 \cdot 1(43 \cdot 4,57 \cdot 8)$ & $44 \cdot 3(38 \cdot 8,50 \cdot 6)$ & $46 \cdot 8(42 \cdot 5,51 \cdot 6)$ & 415 \\
Unweighted base & 209 & 206 & 415 & \\
\hline
\end{tabular}


After deletion of data for those who had died or moved away, 18827 valid potential responders remained.

The survey consisted of three stages. Phase 1 , the initial four page screening questionnaire,

A

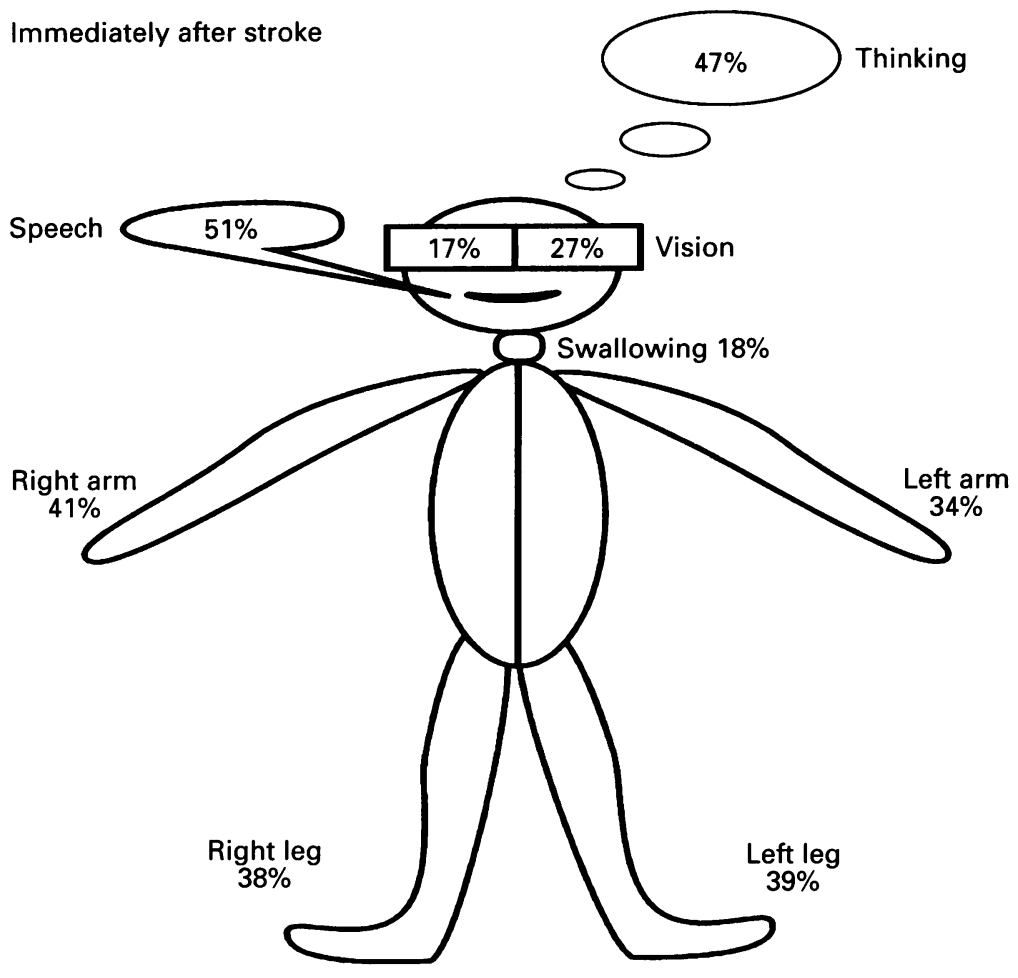

B

At time of prevalence study

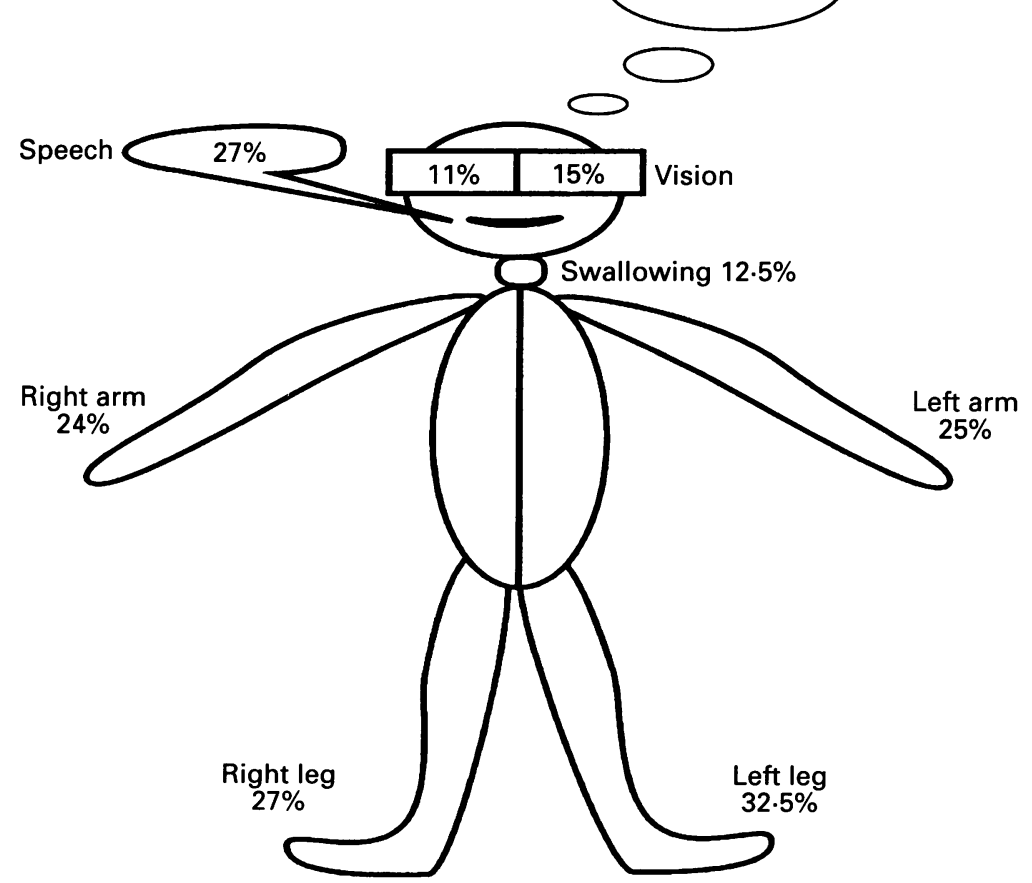

Frequency of body parts affected. was designed to identify all those who thought they had had a stroke. Phase 2, the more detailed questionnaire, was designed to improve specificity by identifying true strokes. Phase 3, involving home visits by a research nurse, consisted of a random sample of those identified from phase 2 as having had a stroke and was designed to validate diagnosis.

\section{VALIDITY}

The questionnaires were piloted on a sample of 1000 patients aged $19+$ in a general practice in north Leeds, where a diagnostic index was available to validate self reported disease. The questionnaire asked, "Have you ever been told by a doctor or other health professional that you have had a stroke?". Of 761 valid cases, $23(3 \%)$ of the pilot sample reported positive for stroke. (This age group was selected to allow us to address methodological issues concerning prevalence of not just stroke but also arthritis). A random sample of 150 of those who reported negative for stroke was confirmed against the diagnostic index. One negative responder was identified as having had a transient ischaemic attack rather than a stroke, thus false negatives were deemed to be absent.

Those who reported positive for stroke were given a more detailed 12 page questionnaire (phase 2). This sought information on a variety of topics such as disability, dependency, and utilisation of hospital and community services. It included the Nottingham health profile (NHP), ${ }^{4}$ as a means of assessing health status, and a series of manikins to determine those parts of the body originally and currently affected. Respondents were asked to indicate on the first manikin those parts of the body which were affected immediately after the stroke. The question "Did these symptoms last for more than 24 hours?" was designed to distinguish true strokes from transient ischaemic attacks. Respondents were encouraged to seek help in completing the questionnaire if necessary. Those who did so were asked to indicate the type of help needed, for example "writing", "understanding the questions".

For the main survey, the initial questionnaire (phase 1) was posted at the beginning of June 1993. Non-responders were sent further copies of the questionnaire, up to a maximum of three, on separate occasions over the next 12 weeks. The more detailed phase 2 questionnaire was sent to all those who reported that they had had a stroke.

\section{RESPONSE AND BIAS}

The phase 1 questionnaire was posted in four waves, the initial post and three further follow ups to non-responders. An $87 \%$ response rate was achieved. For each of the four waves the prevalence of stroke was found to be approximately $5 \%$. Thus as successive waves of non-responders were followed up, reported stroke prevalence remained the same. In this way response bias with regard to the attribute of interest was deemed to be absent. ${ }^{5}$ 
Table 2 Age specific prevalence rates of impairment

\begin{tabular}{|c|c|c|c|c|c|}
\hline \multirow[t]{2}{*}{ Impairment per 1000} & \multicolumn{5}{|l|}{ Age group (y) } \\
\hline & $55-64$ & $65-74$ & $75-84$ & $85+$ & All 55+ \\
\hline $\begin{array}{l}\text { Speech } \\
\text { Thinking } \\
\text { Vision - right eye } \\
\text { Vision - left eye } \\
\text { Swallowing } \\
\text { Right arm } \\
\text { Right leg } \\
\text { Left arm } \\
\text { Left leg }\end{array}$ & $\begin{array}{l}4 \cdot 7(2 \cdot 6,7 \cdot 8) \\
6 \cdot 4(4 \cdot 0,9 \cdot 8) \\
1 \cdot 8(0 \cdot 7,3 \cdot 9) \\
2 \cdot 1(0 \cdot 8,4 \cdot 3) \\
1 \cdot 5(0 \cdot 5,3 \cdot 5) \\
4 \cdot 7(2 \cdot 6,7 \cdot 8) \\
4 \cdot 2(2 \cdot 3,7 \cdot 1) \\
3 \cdot 4(1 \cdot 7,6 \cdot 1) \\
2 \cdot 9(1 \cdot 3,5 \cdot 5)\end{array}$ & $\begin{array}{r}12 \cdot 8(9 \cdot 1,17 \cdot 4) \\
12 \cdot 8(9 \cdot 1,17 \cdot 4) \\
3 \cdot 9(2 \cdot 0,6 \cdot 8) \\
5 \cdot 3(3 \cdot 0,8 \cdot 6) \\
3 \cdot 2(1 \cdot 5,5 \cdot 9) \\
11 \cdot 1(7 \cdot 7,15 \cdot 5) \\
12 \cdot 0(8 \cdot 5,16 \cdot 6) \\
9 \cdot 5(6 \cdot 4,13 \cdot 7) \\
12 \cdot 0(8 \cdot 5,16 \cdot 6)\end{array}$ & $\begin{array}{c}20 \cdot 7(15 \cdot 1,28 \cdot 2) \\
31 \cdot 9(24 \cdot 6,40 \cdot 8) \\
7 \cdot 7(4 \cdot 3,12 \cdot 7) \\
13 \cdot 1(8 \cdot 6,19 \cdot 3) \\
15 \cdot 2(10 \cdot 3,21 \cdot 7) \\
21 \cdot 4(15 \cdot 5,28 \cdot 9) \\
26 \cdot 9(20 \cdot 2,35 \cdot 0) \\
21 \cdot 2(15 \cdot 3,28 \cdot 6) \\
33 \cdot 4(25 \cdot 8,42 \cdot 4)\end{array}$ & $\begin{array}{l}26 \cdot 1(14 \cdot 9,42 \cdot 3) \\
23 \cdot 6(13 \cdot 2,38 \cdot 9) \\
18 \cdot 1(9 \cdot 0,32 \cdot 4) \\
21 \cdot 9(12 \cdot 0,36 \cdot 8) \\
11 \cdot 7(4 \cdot 7,24 \cdot 1) \\
14 \cdot 1(6 \cdot 5,26 \cdot 8) \\
13 \cdot 4(5 \cdot 8,26 \cdot 4) \\
35 \cdot 5(22 \cdot 3,53 \cdot 6) \\
36 \cdot 6(23 \cdot 2,54 \cdot 9)\end{array}$ & $\begin{array}{c}12 \cdot 6(10 \cdot 4,15 \cdot 2) \\
15 \cdot 5(13 \cdot 1,18 \cdot 4) \\
5 \cdot 0(3 \cdot 7,6 \cdot 7) \\
7 \cdot 0(5 \cdot 4,9 \cdot 0) \\
5 \cdot 8(4 \cdot 3,7 \cdot 6) \\
11 \cdot 3(9 \cdot 3,13 \cdot 8) \\
12 \cdot 6(10 \cdot 4,15 \cdot 2) \\
11 \cdot 7(9 \cdot 6,14 \cdot 2) \\
15 \cdot 2(12 \cdot 8,18 \cdot 0)\end{array}$ \\
\hline
\end{tabular}

Table 3 Age and sex specific prevalence rates per 1000 from three studies

\begin{tabular}{|c|c|c|c|c|c|c|c|c|c|}
\hline \multirow{2}{*}{$\begin{array}{l}\text { Age group } \\
(y)\end{array}$} & \multicolumn{3}{|l|}{ Male } & \multicolumn{3}{|l|}{ Female } & \multicolumn{3}{|l|}{ Total } \\
\hline & Copenhagen & Finland & Yorkshire & Copenhagen & Finland & Yorkshire & Copenhagen & Finland & Yorkshire \\
\hline \multirow{4}{*}{$\begin{array}{l}55-64 \\
60-69 \\
65-74 \\
70+ \\
75+\end{array}$} & & $22 \cdot 9$ & $21 \cdot 6(15 \cdot 0,30 \cdot 2)$ & \multirow[b]{2}{*}{$8 \cdot 45$} & $14 \cdot 8$ & $11 \cdot 4(6 \cdot 9,17 \cdot 8)$ & \multirow[b]{2}{*}{$11 \cdot 7$} & $18 \cdot 7$ & \multirow{4}{*}{$\begin{array}{l}16 \cdot 4(12 \cdot 3,21 \cdot 5) \\
26 \cdot 7(21 \cdot 4,32 \cdot 8) \\
39 \cdot 8(33 \cdot 3,47 \cdot 7) \\
75 \cdot 7(67 \cdot 5,84 \cdot 9) \\
95 \cdot 1(83 \cdot 9,107 \cdot 8\end{array}$} \\
\hline & 16.5 & 30 & $33.9(25 \cdot 4,44.3)$ & & 140 & $20 \cdot 1(14 \cdot 0,28 \cdot 2)$ & & $2 \Omega$ & \\
\hline & $45 \cdot 9$ & & $82 \cdot 2(68 \cdot 9,98 \cdot 0)$ & \multirow[t]{2}{*}{$16 \cdot 3$} & & $71 \cdot 7(61 \cdot 9,83 \cdot 1)$ & \multirow[t]{2}{*}{$31 \cdot 6$} & $24 \cdot 9$ & \\
\hline & & $27 \cdot 5$ & $108 \cdot 7(87 \cdot 8,132.9)$ & & $35 \cdot 1$ & $87.9(74 \cdot 5,103 \cdot 7)$ & & $32 \cdot 4$ & \\
\hline
\end{tabular}

Phase 2 achieved a $76 \%$ response rate from four waves and showed some bias in response. Those reporting dependency upon others at phase 1 for dressing, for getting in or out of bed, or for getting in and out of the house were less likely to return the questionnaire. Older respondents were also less likely to respond to the questionnaires in general, although these differences did not reach statistical significance. Data were therefore weighted by non-response for age, sex, and dependency within each agesex group.

For prevalence estimates, $95 \%$ confidence intervals were calculated according to Schoenberg. ${ }^{6}$

\section{Results}

Table 1 shows the age-sex specific prevalence rates for survivors of stroke. Base numbers given are unweighted for sample fraction and non-response. We estimate that $47 / 1000(95 \%$ CI $42 \cdot 5,52 \cdot 0$ ) people aged 55 years or more have survived a stroke. The prevalence of stroke among males is higher than among females in all but those aged $85+$, although overlapping confidence intervals show that there is no significant difference between the sexes. This pattern was also found for the incidence of stroke in the Oxfordshire community stroke project. ${ }^{3}$ In the current study, prevalence in those aged 75 years and over is much higher than previously reported.

More than half of all strokes reported had occurred since the beginning of 1990 . Eighty per cent of respondents had experienced one stroke, $13.0 \%$ had experienced two, and $7 \cdot 0 \%$ three or more. The mean time since stroke for each age group showed a clear trend but was not significantly different, being $7 \cdot 1$ years $(95 \%$ CI $4.9,9.3$ ) for 55-64 year old respondents; $6 \cdot 5$ years $(5 \cdot 1,8 \cdot 0)$ for $65-74$ year old respondents; $5 \cdot 1(3 \cdot 7,6 \cdot 4)$ for $75-84$ year olds and $4 \cdot 7$ years $(3 \cdot 2,6 \cdot 2)$ for those 85 years and over.

Although an accurate knowledge of numbers is essential for purchasers, it is not sufficient to commission services. For this it is necessary to know the distribution and severity of impairments and disabilities to allow a judgement to be made on the range and type of services required. Figure A illustrates the reported frequency of impairments immediately after the stroke. Speech impairments $(51 \%)$ and cognitive impairments $(47 \%)$ were the most common problems.

Twenty three per cent of respondents reported full recovery from stroke. There was no significant difference between sexes $\left(\chi^{2} 1 \cdot 84\right.$; $\mathrm{p}=0.175)$ or age group $\left(\chi^{2} 3.32 ; \mathrm{p}=0.50\right)$ in the proportion reporting full recovery. Figure $B$ shows the frequency of impairments at the time of the prevalence study. There was no significant difference between the age groups in the proportions of these residual impairments. Cognitive impairments (33\%) and problems with lower limbs (33\% for right leg; $27 \%$ for left leg), together with speech $(27 \%)$ were the most common residual impairments. Age specific prevalence rates for those with residual impairments are shown in table 2.

In addition to these impairments, $55 \%$ of respondents reported disability in that they required help from another person in one or more of 10 activities of daily living. Five of these were concerned with mobility; getting out of bed, getting up from a chair, going up and down stairs, walking inside the house, and walking outside the house. The remaining five concerned self care; cutting food, washing the face and combing hair, dressing, getting on and off the toilet and taking a bath or shower.

The proportions of the four age groups who reported disability resulting in dependency in one or more of these activities varied from $24 \cdot 7 \%$ of the $55-64$ year olds; $45 \cdot 9 \%$ of $65-74$ year olds; $62 \cdot 3 \%$ of $75-84$ year olds to $75 \cdot 3 \%$ of those aged 85 and over. This variation with age was highly significant $\left(\chi^{2} 39 \cdot 45 \mathrm{p}<0.0001\right)$.

\section{Discussion}

A comparison of the estimated prevalence rates in Yorkshire with two recent European studies ${ }^{78}$ 
also quoted in the UK Health Service Guide to Purchasers, ${ }^{2}$ illustrates the considerable difference between calculated rates (table 3 ). Although both the European studies had the advantage over the Yorkshire study in that the diagnosis of stroke was confirmed by interview or examination of medical records, each exhibit aspects that might lead to some question of the accuracy of the estimation of prevalence rates. The Finnish study, a cohort study, indicated that the incidence of strokes in men over 75 years of age was 33.7 per 1000 , while the prevalence rate for men over 75 years of age was given as 27.5 per $1000 .^{9}$ As prevalence is usually considered to be a function of incidence and duration of survival, these figures seem surprising. Similar criticism may be made of the prevalence rates for females aged $65-74$ and $75+$. Indeed, the authors comment on "the unexpectedly low prevalence rates in males aged $75+$ and females aged 65-74".

The Copenhagen study involved participants travelling to a hospital on a specified date to take part in the study and the authors report under-representation of the $80+$ age group, the very group that exhibits the highest incidence, ${ }^{3}$ only $32 \%$ of whom participated.

The current study estimated the prevalence of stroke among the population aged 55 or more only. If, however, extrapolating from the Oxford study, it is assumed that an additional $8 \%$ of strokes occurred among those aged 54 or under, and assuming similar mortality rates, then the prevalence rate among the whole population may be estimated as $1470 / 100000$; more than twice the figure commonly used. If the Finnish study were used to estimate prevalence in north Yorkshire, ${ }^{7}$ it would give an estimate for survivors which is only $54 \%$ of the current study. Similarly, the Copenhagen study would estimate only $44 \%$ of survivors. ${ }^{8}$

One explanation of this higher prevalence could be a substantial improvement in survival of stroke patients in the $1980 \mathrm{~s}$, recently reported from the USA. ${ }^{10}$ The reasons for this "unexpected yet remarkable trend" are postulated as improved supportive and rehabilitative care as well as a change in the natural history of the disease. If this trend has also occurred in the UK it will have contributed to a higher than expected prevalence rate.

Subtracting the $23 \%$ of survivors who reported full recovery produces an estimated prevalence rate of survivors with impairments of $1130 / 100000$ and an estimated 620/100000 who are dependent in aspects of mobility or activities involved with self care. If current guide-lines are used this study suggests that estimates of the needs of stroke survivors for medium to long term care are likely to be seriously under estimated.

These data have already given rise to a review of hospital admission rates in the five localities of north Yorkshire; to an examination of provision of benefits and services in the community, and to a study examining the process of decision making by care managers regarding service provision. Further analysis is under way to examine the receipt of inpatient and outpatient treatment and the provision of planned discharge from hospital.

Clearly purchasers will need to take into account data on incidence for planning acute services as well as such prevalence data which indicate longer term needs after stroke.

The authors acknowledge funding for the project from the Yorkshire Region Health Cube Needs Assessment Project and the Stroke Association. Thanks also to the Grange Medical Centre, Seacroft, Leeds.

1 Terent A. Stroke morbidity. In: Whisnant JP, ed. Stroke populations, cohorts, and clinical trials. Oxford: Butterworthpopulations, cohorts, and clinical trials. Oxford: Butter

2 Stevens A, Rastery J, eds. Health care needs assessment. Vol 1. Oxford: Radcliffe Medical Press, 1994;178:178-9.

3 Bamford J, Sandercock P, Dennis M, Warlow C, Jones $\mathrm{L}$, McPherson $\mathrm{K}$, et al. A prospective study of acute cerebrovascular disease in the community: the Oxfordshire community stroke project 1981-1986. Methodology, demography and incident cases of first-ever stroke. Neural Neurosurg Psychiatry 1988;51:1373-80.

4 Hunt SM, McEwen J, McKenna SP. Measuring health status. London: Croom Helm, 1986.

5 Tennant A, Badley EM. Investigating non-response bias in a survey of disablement in the community: Implications for survey methodology. $\mathcal{f}$ Epidemiol Community Health for survey meth

6 Schoenberg BS. Calculating confidence intervals for rates and ratios. Neuroepidemiology 1983;2:257-65.

7 Aho K, Reunanen A, Aromaa A, Knekt P, Maatela J. Prevalence of stroke in Finland. Stroke 1986;17:681-6.

8 Sorensen PS, Boysen G, Jensen G, Schnohr P. Prevalence of stroke in a district of Copenhagen. Acta Neurol Scandinav 1982;66:68-81.

9 Reunanen A, Aho K, Aromaa A, Knekt P. Incidence of stroke in a Finnish prospective population study. Stroke 1986;17:675-81.

10 Shahar E, McGovern PG, Spafka JM, Pankow JS, Doliszny $\mathrm{KM}$, et al. Improved survival of stroke patients during the 1980's. Stroke 1995;6:1-6. 